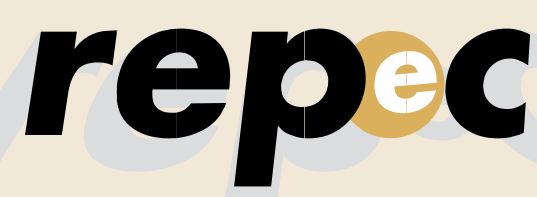

REPeC, Brasília, v. 9, n. 3, art. 6, p. 331-354, jul./set. 2015

Disponível online em www.repec.org.br

DOI: http://dx.doi.org/10.17524/repec.v9i3.1176
Revista de Educação e Pesquisa em Contabilidade

Journal of Education and Research in Accounting

Revista de Educación e Investigación en Contabilidad

Periódico Trimestral, digital e gratuito publicado pela Academia Brasileira de Ciências Contábeis

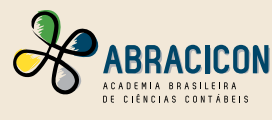

\title{
A Divulgação do Risco nas Demonstrações Financeiras: Uma Análise ao Anexo das Sociedades Não Financeiras Portuguesas
}

\begin{abstract}
Resumo
O presente estudo tem por objetivo analisar a divulgação do risco efetuada por parte das sociedades não financeiras Portuguesas cotadas na Euronext de Lisboa ao longo dos anos de 2011 e 2012. Foram analisadas as características da informação divulgada em matérias ligadas ao risco, tendo em conta o âmbito temporal, o caráter quantitativo ou qualitativo da informação, a natureza e a classificação do risco divulgado. Os dados para este estudo foram recolhidos a partir da análise de conteúdo ao anexo dos relatórios e contas (contas consolidadas) das entidades pertencentes à população, durante o período de 2011 e 2012, resultando em uma população de 36 entidades. Os referidos dados foram posteriormente, submetidos a técnicas de análise univariada e bivariada, baseada em testes não paramétricos, nomeadamente o teste de Wilcoxon. Os resultados demonstram que predomina a divulgação de informação financeira de forma qualitativa, referente ao passado, e classificada como "boas notícias". Pretende-se que os resultados desta investigação possam contribuir para a compreensão do tema desenvolvido, como é o caso dos elementos que se encontram na base da divulgação de informação de matérias ligadas ao risco.
\end{abstract}

Palavras - Chave: Anexo, Controlo Interno, Divulgação, Teorias Justificativas do Risco, Risco

\author{
Maria de Lima e Silva \\ Mestrado pelo Instituto Superior de \\ Contabilidade e Administração de Lisboa \\ e Auditora da Pricewaterhouse Coopers. \\ Contato: Rua Augusto Gil, 29, Lisboa. \\ Lisboa-Portugal. CEP.: 1000-063. \\ E-mail: marialimsilva@gmail.com
}

Fábio Henrique Ferreira de Albuquerque

Doutorado pela Universidade de Extremadura e Professor Adjunto no Instituto Superior de Contabilidade e Administração de Lisboa. Contato: Av. Miguel Bombarda, 20, Lisboa. LisboaPortugal. CEP.: 1069-035.

E-mail: fhalbuquerque@iscal.ipl.pt

Manuela Maria Marcelino
Mestrado pelo Instituto Superior de
Contabilidade e Administração de Lisboa
e Técnica Superior na Área Financeira e
Patrimonial na Faculdade de Farmácia
da Universidade de Lisboa. Contato:
Av.Professor Gama Pinto, Lisboa. Lisboa-
Portugal. CEP.: 1649-003.
E-mail: mmarcelino@ff.ulisboa.pt
Joaquín Texeira Quirós
Doutorado pela Universidade de
Extremadura e Professor Coordenador
da Universidade Autónoma de Lisboa.
Contato:Rua de Santa Marta, 56, Lisboa.
Lisboa-Portugal. CEP.: 1169-023.
E-mail: jquiros@ual.pt

Manuela Maria Marcelino Mestrado pelo Instituto Superior de Contabilidade e Administração de Lisboa e Técnica Superior na Área Financeira e Patrimonial na Faculdade de Farmácia da Universidade de Lisboa. Contato: Av.Professor Gama Pinto, Lisboa. LisboaPortugal. CEP.: 1649-003.

E-mail: mmarcelino@ff.ulisboa.pt

Joaquín Texeira Quirós

Doutorado pela Universidade de Extremadura e Professor Coordenador da Universidade Autónoma de Lisboa. Lisboa-Portugal. CEP.: 1169-023.

E-mail: jquiros@ual.pt 


\section{Introdução}

Com a globalização da economia, fez-se sentir um crescente aumento da competitividade, que forçou as entidades a inovarem por forma a criar valor para os seus stakeholders. A problemática da fraude, pela sua componente económica e social, é uma questão bastante presente e relevante em diversas esferas da sociedade.

Assim, e perante a frequente divulgação de casos de fraude em entidades multinacionais, houve duas correntes que, mais recentemente, emergiram, uma nos Estados Unidos da América (EUA), com o advento da Sarbanes-Oxley Act (SOX), conhecida como Lei Sarbanes-Oxley, e outra na Europa. Em ambos os casos, têm como target as empresas cotadas em mercados regulamentados, o que não evitou, contudo, o desaparecimento dos crimes económicos.

Todas as entidades enfrentam incertezas, sendo o desafio dessas entidades determinar o nível de incerteza que estão dispostas a aceitar. $\mathrm{O}$ risco pode ser definido como uma probabilidade de que algum acontecimento desfavorável venha a ocorrer e que afete a entidade, podendo advir das mais variadas situações e estar ligado a decisões de investimentos, criação de um novo produto, estratégia de marketing, competitividade de mercado, etc. Sob esse ponto de vista, o risco é um fator inerente à própria entidade. A gestão de risco permite identificar, avaliar e administrar riscos diante de incertezas e integra o processo de criação de valor. Entre outros documentos identificados na literatura, os relatórios e modelos de controlo interno de referência internacional, conhecidos como Relatório Treadway, Relatório Cadbury, Relatório Turnbull, Criteria of Control Framework (Coco), Committee of Sponsoring Organizations (Coso) e Control Objectives for Information and Related Technology (Cobit), antecedentes da SOX, identificam questões relevantes relacionadas com a gestão do risco.

A adequada divulgação das políticas contabilísticas seguidas pela entidade e a observação das características qualitativas que estão na base da preparação das demonstrações financeiras (DF) - conjuntamente com o adequado cumprimento do referencial contabilístico (normas contabilísticas e de relato financeiro) aplicável - constituem a primeira garantia da qualidade e, bem assim, da utilidade da informação financeira por parte dos diversos utilizadores dessa informação. Igualmente relevantes no contexto das divulgações a efetuar por uma entidade, encontram-se os principais pressupostos relativos ao futuro e outras fontes de incerteza das estimativas efetuadas à data do balanço que apresentem um risco significativo de provocar um ajustamento material nas quantias escrituradas de ativos e passivos durante o próximo ano financeiro.

De facto, a relevância desta matéria encontra-se intrinsecamente relacionada com a capacidade que têm as referidas fontes de incerteza, presentes na elaboração do relato, de influenciar a tomada de decisão dos utentes. Note-se, no entanto, que embora o relato do risco, lato sensu, não seja uma exclusividade das DFs, o alcance da Estrutura Conceptual (EC), como um documento que estabelece as características qualitativas que a informação financeira deve observar, encontra-se limitado a essa informação, particularmente no contexto do anexo. O risco divulgado no anexo é, ainda, complementado com as disposições legais internas (nacionais) relevantes, relativamente, a essa matéria.

O presente estudo pretende analisar, em linhas gerais, o risco divulgado no relatório e contas (RC), mais precisamente no anexo, por parte das entidades cotadas na Euronext de Lisboa durante os anos de 2011 e 2012. Após a recolha então efetuada, a população identificada para este estudo encontra-se constituída por 36 entidades. O estudo incide sobre as divulgações associadas ao risco que assumam um caráter obrigatório divulgado no relato financeiro das entidades, em particular no anexo, seja por via da Internacional Accounting Standard (IAS) 1: "Presentation of Financial Statements" do International Accounting Standards Board (Iasb), seja por força do cumprimento de requisitos obrigatórios previstos na legislação nacional, nomeadamente no Código das Sociedades Comerciais (CSC).

O objetivo do presente trabalho consiste na análise da informação divulgada no que toca ao âmbito temporal (backward versus ( $v s$.) forward), ao caráter da informação (qualitativa vs. quantitativa) e, ainda, quanto à natureza da divulgação ("boas" vs. "más" notícias) e à respetiva classificação do risco divulgado (financeiro $v s$. não financeiro). 
A divulgação de riscos para efeitos deste estudo foi classificada em duas categorias principais:

- Riscos financeiros, onde se incluem os riscos de mercado, de liquidez, de crédito e de capital; e

- Riscos não financeiros, que incluem os riscos operacionais, de negócio (ou estratégicos) e legais (ou de conformidade).

Para o efeito, o risco analisado neste estudo abarca as exigências de divulgação dos "principais pressupostos relativos ao futuro e outras principais fontes de incerteza das estimativas efetuadas", previsto na IAS 1 ( $(116)$, e em legislação nacional específica (CSC).

Esta pesquisa insere-se, assim, no contexto da divulgação do risco no relato financeiro consolidado das entidades (não financeiras) em Portugal a partir da análise do anexo. Nesse sentido, a seleção desta fonte de recolha de informação apresenta-se como uma das principais motivações para a realização desta investigação, na medida em que a generalidade dos estudos relacionados com essa temática, a saber, a divulgação do risco, tem-se centrado, maioritariamente, na análise do relatório de gestão e não especificamente nas DF, onde se inclui o anexo.

\section{Enquadramento teórico}

A maior parte dos estudos efetuados sobre a divulgação do risco baseia-se em evidências empíricas a partir de regulamentações de origem anglo-saxónicas (Abraham \& Cox, 2007; Deumes \& Knechel, 2008; Lajili \& Zéghal, 2005; Linsley \& Shrives, 2006; Oliveira, Rodrigues \& Craig, 2011a), bem como no âmbito dos países continentais (Beretta \& Bozzolan, 2004).

Com a publicação por parte dos principais organismos de normas ou recomendações específicas em matéria de divulgação de informação sobre instrumentos financeiros, em particular sobre instrumentos derivados, têm sido vários os autores que se preocupam em estudar o grau de cumprimento com as exigências de divulgação contidas nas normas, ou com o impacto provocado pela obrigatoriedade de adoção de determinada norma na informação divulgada, por parte das entidades financeiras. Sobre este assunto, Lemos e Rodrigues (2011, p. 10) referem que "apesar das instituições bancárias utilizarem instrumentos derivados, [...] a informação que divulgam, nos seus documentos de prestações de contas [...] é, ainda, bastante limitado". No estudo de Lemos e Rodrigues (2011), os autores analisaram o nível de divulgação sobre os instrumentos financeiros derivados, por parte das 34 entidades financeiras que operaram em Portugal durante o exercício económico de 2009. Deste estudo resultou que a informação qualitativa tem uma divulgação superior à informação quantitativa. Também Alves (2005) seguiu por uma análise semelhante, ao analisar o grau de cumprimento para com as recomendações do Comité da Basileia (sobre risco operacional), relativamente aos maiores bancos do Brasil e nove bancos dos EUA e da Europa. O autor identificou um aumento do nível de divulgação no ano de 2003 para 2004, tanto no Brasil como no estrangeiro, e que os bancos dos EUA e da Europa divulgaram mais informação do que os bancos do Brasil. Linsley e Shrives (2006), ao analisarem a informação divulgada nos maiores bancos do Reino Unido e do Canadá, constataram que a informação divulgada que apresenta um maior foco é a informação quantitativa e a informação sobre as políticas de gestão.

Em Portugal, Oliveira et al. (2011a) analisaram os relatórios anuais dos 101 bancos comerciais portugueses que divulgaram a informação no Banco de Portugal a 31 de dezembro de 2007. De acordo com os resultados obtidos, verificou-se que a divulgação de informação relacionada com o risco é reduzida, tendo por base as entidades que adotam o normativo nacional. Tais resultados corroboraram a visão de que a adoção das IAS/International Financial Reporting Standarts (IFRS) tem levado a um aumento de divulgação de matérias ligadas ao risco.

Guthrie, Petty, Youngvanich e Ricceri (2004) referem que o relatório anual revela-se como uma fonte de obtenção de informação bastante útil, uma vez que os gestores das entidades utilizam os relatórios como veículo de sinalização de informação importante ao mercado. É, talvez, o documento mais divulgado pelas entidades e que é apresentado numa base regular. 
Embora o relatório de gestão seja considerado como uma ferramenta de comunicação por parte das entidades, outros autores, nos últimos anos, têm usado outros meios como fonte de informação. É o caso de Hernández-Madrigal, Blanco-Dopico e Aibar-Guzmán (2012), que analisaram o "corporate governance annual reports" publicado nos websites das entidades.

O relatório anual das entidades é um documento formal que contém informações quantitativas, narrativas e gráficos, e que permite aos stakeholders obter informação sobre a situação financeira, e direção esperada da entidade. Trata-se, também, de uma resposta às exigências de divulgação obrigatória dos órgãos reguladores (Yampolskaya, 2006). O relatório anual deve conter tanto informação financeira como informação não financeira, de modo a proporcionar uma imagem verdadeira e abrangente da situação da entidade. As informações contidas no relatório precisam ser de confiança, de forma a evitar falhas do mercado (Johansson \& Thöonberg, 2011).

Uma das possíveis classificações relativas ao risco serve à análise entre a quantidade de informação numérica/quantitativa e a informação não numérica/qualitativa divulgada pelas entidades nesse âmbito, suportando-se tais estudos na hipótese de que as entidades divulgam mais informação de natureza estritamente qualitativa, comparativamente com a informação de natureza quantitativa (Beretta \& Bozzolan, 2004; Lajili \& Zéghal, 2005; Linsley \& Shrives, 2006; Oliveira et al., 2011a).

Os estudos relacionados com a divulgação do risco baseiam-se em análises de conteúdo à informação divulgada a partir de uma prévia classificação dos riscos em categorias ou tipologias de risco.

A análise de conteúdo é utilizada em uma perspetiva qualitativa ou quantitativa (Hernández-Madrigal et al., 2012). A classificação dos riscos em tais categorias baseia-se, fundamentalmente, na criação de um índice de divulgação associado à tipologia do risco definido o qual, numa fase seguinte, serve, posteriormente, à análise das hipóteses definidas no estudo (Beretta \& Bozzolan, 2004; Deumes \& Knechel, 2008). Numa perspetiva quantitativa, as forma de análise da quantidade do cumprimento da divulgação do risco, passa por: "contar" frases (Beretta \& Bozzolan, 2004; Ereira, 2007; Lajili \& Zéghal, 2005; Linsley \& Shrives, 2006; Michiels, 2008; Oliveira et al., 2011a), por registar o número de palavras (Abraham \& Cox, 2007; Lajili \& Zéghal, 2005), ou registar o número de parágrafos (Hassan, 2012).

Em suma, relativamente à tipologia dos riscos, identificam-se as classificações relativas aos riscos de controlo, riscos financeiros, riscos operacionais, risco de negócio ou estratégicos, riscos de ordem legal, além do risco ambiental e de segurança (Ereira, 2007; Hernández-Madrigal et al., 2012; Höring \& Gründl, 2011; Jiang, 2008; Kongprajya, 2010; Meijer, 2011; Michiels, 2008; Oliveira \& Rodrigues, 2011; Puga, 2012; Vandemaele, Vergauwen \& Michiels, 2009; Yampolskaya, 2006), ou ainda abordagens baseadas nos riscos identificados nos modelos de controlo interno de referência internacional (Deumes \& Knechel, 2008; Tröster, 2005). No estudo efetuado por Linsley e Shrives (2006), os autores concluíram que a divulgação do risco financeiro era bastante inferior à divulgação por parte do risco operacional, com apenas $23 \%$.

$\mathrm{Na}$ literatura abordada, encontraram-se, igualmente, estudos que classificam a informação relativa ao risco consoante a natureza do conteúdo da informação divulgada em "boa", "má" ou "neutra" (Ereira, 2007; Linsley \& Shrives, 2006; Oliveira \& Rodrigues, 2011; Puga, 2012). Linsley e Shrives (2006), designadamente, concluíram que a natureza da divulgação de notícias más ronda os $20 \%$, as boas notícias $26 \%$ e as notícias neutras respeitam a $54 \%$ das divulgações.

Outra classificação dos riscos passa por classificá-los numa visão backward-looking ou forward-looking (Beattie, Mcinnes \& Fearnley, 2004; Beretta \& Bozzolan, 2004; Lajili \& Zéghal, 2005; Linsley \& Shrives, 2006; Oliveira et al., 2011a; Puga, 2012; Solomon, Solomon, Norton \& Joseph, 2000). Alguns estudos, como, por exemplo, o estudo de Linsley e Shrives (2006), demonstram a relutância na divulgação de informações backward-looking, ao passo que estudos como o de Beattie et al. (2004), Beretta e Bozollan (2004) e Puga (2012) demonstraram o oposto.

Solomon et al. (2000) constataram, ainda, que os investidores preferem obter informações detalhadas/específicas sobre os riscos e não uma informação generalizada dos riscos. 
O estudo de Oliveira et al. (2011a) difere dos resultados de Linsley e Shrives (2006). A diferença pode ser atribuída aos contextos ambientais divergentes dos estudos, ou seja, há muito menos ênfase nos interesses dos investidores e nas necessidades de informação dos mercados de valores mobiliários em Portugal do que no Reino Unido.

De acordo com diversos autores, para melhorar a qualidade da divulgação do risco é recomendado que as entidades quantifiquem, na medida do possível, a dimensão do risco (Beretta \& Bozzolan, 2004; Linsley \& Shrives, 2006), o que possibilita, aos utilizadores da informação divulgada, calcular o seu impacto na entidade. Na medida em que se torna difícil quantificar esses riscos, uma vez que estão associados diversos entraves (como por exemplo falta de dados), existe uma maior informação não monetária nas divulgações (Ereira, 2007).

De acordo com as evidências das teorias justificativas do relato voluntário, as duas teorias mais verificadas na literatura como justificativas do relato voluntário são a teoria da Agência e a teoria da Sinalização.

A teoria da Agência e a teoria da Legitimidade apontam que as entidades de maior dimensão apresentam um maior interesse público e, como tal, apresentam necessidades adicionais de divulgação, suportando a existência de relação e/ou associação e/ou diferenças significativas entre a dimensão das entidades e a divulgação do risco (Beattie et al., 2004; Deumes, 2008; Ereira, 2007; Höring \& Gründl, 2011; Jiang, 2008; Kongprajya, 2010; Linsley \& Shrives, 2006; Meijer, 2011; Rajab \& Handley-Schachler, 2009; Tröster, 2005; Vandemaele et al., 2009; Yampolskaya, 2006).

A teoria da Sinalização refere que as entidades mais rentáveis poderão querer sinalizar a sua situação, divulgando, nesse caso, mais informação, para se poderem distinguir das entidades menos rentáveis do mercado, isto por forma a explicarem as razões do seu menor desempenho e assegurarem perante o mercado, as expetativas de crescimento futuro. Assim, há quem entenda que haja uma relação entre o nível da divulgação do risco e a performance (Ereira, 2007).

A teoria da Agência suporta igualmente hipóteses de relação e/ou associação e/ou análise de diferenças entre a divulgação de matérias relativas ao risco e o próprio risco da entidade (baseado, designadamente, no endividamento empresarial), rendibilidade e a política de distribuição de dividendos (Ereira, 2007; Höring \& Gründl, 2011; Kongprajya, 2010; Michiels, 2008; Oliveira \& Rodrigues, 2011; Rajab \& Handley-Schachler, 2009; Tröster, 2005; Vandemele et al., 2009), assim como entre o setor ou mercado de enquadramento das entidades analisadas (Deumes, 2008; Jiang, 2008; Kongprajya, 2010; Oliveira \& Rodrigues, 2011; Rajab \& Handley-Schachler, 2009; Yampolskaya, 2006).

Em síntese, na revisão feita aos diversos estudos acerca do nível de risco divulgados pelas entidades, quer seja de forma voluntária ou de forma obrigatória, verifica-se, na generalidade, a relação positiva entre o nível de divulgação e a dimensão da entidade. Esta relação positiva entre a dimensão da entidade e a quantidade de informação divulgada pode ser explicada pelo facto de as grandes entidades apresentarem um maior número de stakeholders a quem têm que reportar informação relacionada com o risco (Linsley \& Shrives, 2006); ou pelo facto destas entidades enfrentarem mais riscos e, como consequência, apresentarem uma maior quantidade de informação relacionada com o risco (Yamploskaya, 2006).

A relevância da dimensão da entidade no contexto da divulgação do risco é facilmente compreendida pela teoria da Agência, uma vez que destaca o facto de que quanto maior a empresa, maior os custos de agência em virtude da existência de assimetrias informacionais (Zadeh \& Eskandari, 2012).

No que toca ao endividamento, os estudos desenvolvidos pretendem analisar a relação entre o relato efetuado pelas entidades e o seu nível de endividamento. À luz da teoria da Sinalização na sua relação com o custo de capital, designadamente, quanto mais as entidades necessitem de recorrer ao endividamento, maior será a quantidade de informação divulgada (Ereira, 2007).

Semper e Beltrán (2014), designadamente, analisaram se o custo do capital próprio da empresa está, ou não, relacionado com a divulgação de risco. Os resultados obtidos, a partir da análise da informação divulgada nos relatórios de gestão anuais de empresas não financeiras cotadas na Bolsa de Valores de Madrid, entre 2007 a 2009, permitiram verificar uma relação estatisticamente significativa e positiva entre o custo do capital próprio e a divulgação do risco financeiro, não se verificando esta relação entre o custo 
do capital próprio e a divulgação do risco não financeiro. Nesse sentido, Semper e Beltrán (2014) sugerem que as divulgações de risco efectuadas pelas empresas parecem introduzir contingências desconhecidas e fatores de risco, e não apenas uma actualização das informações sobre os riscos conhecidos.

Outros estudos têm-se centrado na componente de corporate governance, onde se inclui a análise de relações/associações e ou diferenças significativas consoante a existência, ou não, de um comité de auditoria ou ao número de administradores não executivos componentes dos órgãos sociais da entidade, a qualidade da auditoria, assim como a estrutura da propriedade de capital e composição dos órgãos sociais, nomeadamente, a concentração do capital e as ações não detidas pelos acionistas maioritários (Abraham \& Cox, 2007; Deumes \& Knechel, 2008; Hernández-Madrigal et al., 2012; Höring \& Gründl, 2011; Jiang, 2008; Michiels, 2008; Tröster, 2005; Vandemaele et al., 2009).

Como ponto aparentemente comum dos estudos mais recentes relativos à divulgação do risco, encontra-se o incremento da divulgação observado nessa matéria, sobretudo por força das maiores exigências prescritas por organismos normalizadores (seja por recomendação de implementação de novas formas de relato seja pela exigência de relato obrigatório).

Exemplo disto é o estudo de Rajab e Handley-Schachler (2009), tendo por base 53 entidades não financeiras cotadas do Reino Unido. Os autores constataram que a divulgação aumentou em determinados períodos de tempo (1998-2000, 1998-2004, 2001-2004), como resultado da aplicação de regulamentações. O estudo de Liu (2006) continha uma população de sete entidades de telecomunicações, cotadas de 2001 a 2006, também do Reino Unido, e verificou um aumento da divulgação no período de 2001 a 2002 e de 2005 a 2006 (este último com uma percentagem superior de número de palavras relacionadas com a divulgação do risco). Oliveira et al. (2011a), ao avaliarem 42 empresas cotadas na Comissão do Mercado de Valores Mobiliários (CMVM), não registaram qualquer aumento na quantidade de informação divulgada sobre o risco como resultado da adopção das IAS e das IFRS. No estudo de Hernández-Madrigal et al. (2012), o período em análise foi dividido em duas partes. A primeira consistiu no período pre-release e a segunda no período pós-release, entre 2006 e 2009. O primeiro período compreendeu os anos 2004 e 2005 e foi precedido pela publicação de importantes códigos e normas, tanto em Espanha, pelo Código Olivencia e o Código Aldama, como noutros países, como a publicação da SOX, do Relatório Winter e do Coso. Os autores identificaram um incremento, ainda que reduzido, na divulgação de informação quantitativa e detalhada sobre os riscos, e uma melhoria progressiva do valor médio dos índices de divulgação do risco no período pós-release, comparativamente ao período pré-release, indicando, assim, uma influência por parte da publicação da legislação. Os resultados sugerem, ainda, o esforço por parte das entidades, no sentido de melhorar a informação divulgada, ainda que limitadas ao cumprimento dos requisitos mínimos estabelecidos por lei, não considerando outra informação útil ao utilizador/investidor.

Abraham e Shrives (2014), por sua vez, desenvolveram um modelo baseado em três questões que pode ajudar a avaliar a divulgação do risco por parte das entidades, nomeadamente: a "divulgação de informações deve ser simultaneamente específica para a empresa e regularmente actualizada"; os "gestores das empresas devem avaliar as divulgações de risco em uma base regular no âmbito dos relatórios anuais"; e as "divulgações no âmbito dos relatórios anuais devem incorporar a discussão de experiências reais de risco". De acordo com os autores, a pesquisa sobre o tema identifica que estas três questões devem ser consideradas pelos gestores relativamente às divulgações de risco, permitindo uma melhoria da qualidade da informação. $\mathrm{O}$ modelo proposto foi então aplicado a quatro empresas do setor de produção e processamento de alimentos pertencentes à FTSE 100, e de forma a avaliar a forma como as divulgações de risco alteraram ao longo do tempo, foram analisados os relatórios anuais para os exercícios de 2002-2007. Os resultados obtidos sugerem que os gestores das empresas preferem fornecer divulgações que são simbólicas, ao invés de substantivas. Abraham e Shrives (2014) argumentam que os fatores institucionais e os custos de propriedade podem contribuir e explicar esse comportamento. Os autores chamam a atenção, ainda, para o papel que as partes interessadas, nomeadamente, os gestores, utilizadores, órgãos reguladores e auditores podem desempenhar na melhoria da qualidade dos relatórios de risco. 
Como técnicas estatísticas identificáveis nos diversos estudos, identificaram-se técnicas de análise de regressão e/ou correlação estatística, em que se incluem os testes de correlação de Pearson e Spearman, bem como outras técnicas de análise multivariada baseadas em análise de fiabilidade, análise factorial e técnicas de análise de componentes principais (Deumes, 2008; Höring \& Gründl, 2011; Meijer, 2011; Michiels, 2008; Puga, 2012; Taylor, Tower \& Neilson, 2010; Tröster, 2005; Vandemaele et al., 2009), consoante a normalidade, ou não, da distribuição das variáveis. Identificam-se ainda estudos que se baseiam em testes de diferenças de média como o $t$-test, o teste de Mann-Whitney-U ou ainda o teste dos sinais e de Wilcoxon e análises de variância ANOVA e Kruskal-Wallis (Hernández-Madrigal et al., 2012; Meijer, 2011; Michiels, 2008; Oliveira \& Rodrigues, 2011; Tröster, 2005; Vandemaele et al., 2009).

Outros estudos procuram, ainda, identificar de que forma a perceção do risco influencia o comportamento dos utilizadores da informação, nomeadamente, no que diz respeito às decisões de compra $\mathrm{e}$ venda de posições por parte dos investidores e/ou o julgamento dos analistas (Deumes, 2008; Slovic, Fischhoff \& Lichtenstein, 1980).

A análise do risco sob a ótica dos utilizadores também assume especial importância, na medida em que, de acordo com Slovic et al. (1980), as divulgações relacionadas com o risco são suscetíveis de serem interpretadas pelos utilizadores das DFs de uma forma diversa da inicialmente pretendida.

No contexto nacional, identificam-se já os estudos de Ereira (2007) e Oliveira e Rodrigues (2011). Contudo, nos referidos estudos, o anexo não foi objeto exclusivo de análise.

\section{Metodologia}

O presente capítulo pretende apresentar as linhas metodológicas gerais seguidas na condução deste estudo.

O objetivo deste estudo reside na análise da divulgação de matérias relativas ao risco identificado no relato financeiro (especificamente no anexo) que assumam um caráter obrigatório, identificados nas diversas fontes legais, seja por via da IAS 1, seja por força do cumprimento de requisitos obrigatórios previstos na legislação nacional, nomeadamente no CSC.

Nesse sentido, a divulgação relativa aos riscos foi classificada em diversas categorias ou atributos principais. Foram criadas quatro hipóteses $(\mathrm{H} 1-\mathrm{H} 4)$, deduzidas a partir da revisão da literatura efetuada nesta área e de forma a atender aos objetivos definidos para este estudo. O desenvolvimento de cada uma das hipóteses será apresentado nos pontos que se seguem.

\subsection{Hipóteses do estudo}

\subsubsection{A divulgação financeira vs. não financeira}

Embora as entidades tenham melhorado a divulgação da informação dos riscos financeiros, esta divulgação não fornece informação suficiente acerca da posição financeira da entidade, uma vez que o desempenho financeiro da mesma é igualmente afetado pelo risco não financeiro (Beretta \& Bozzolan, 2004). Importa, pois, avaliar se a tendência da divulgação do risco das entidades portuguesas respeita mais à informação financeira ou não financeira.

Nos últimos anos, assistiu-se, por parte dos principais organismos emissores de normas, a um progressivo alargamento do âmbito do relato financeiro, de modo a que os riscos e as incertezas inerentes à atividade das entidades possam estar disponíveis aos utilizadores (embora os diferentes subtipos que integram o conceito de risco tenham sido alvo de tratamentos diferentes). Nesse sentido, algumas IAS/IFRS, bem como a legislação societária em termos europeus, designadamente, vieram incorporar nas notas às DFs vários aspetos do risco, designadamente, os requisitos da gestão e da divulgação do risco associado 
a instrumentos financeiros e o efeito das contingências sobre ativos e passivos. Pode-se, pois, afirmar, em termos gerais, a verificação de uma tendência, por parte destes organismos, em introduzir a divulgação do risco no reporte financeiro de uma forma fragmentada, com foco especial no risco financeiro.

Assim, o risco financeiro apresenta-se diretamente introduzido nas normas contabilísticas e de relato financeiro ou em legislação societária (CSC) por meio de requisitos de divulgação, permitindo aos utilizadores aceder à exposição das entidades a estes fatores de risco. As restantes tipologias de risco apresentam-se, em muitos casos, por sua vez, como requisitos voluntários de divulgação (Lajili \& Zéghal 2005) ou tais requisitos são definidos em termos menos precisos, deixando aos administradores a decisão de encontrar a melhor forma de o divulgar (Dobler, 2008; Serrasqueiro, 2011).

Apesar da tendência anteriormente referida, os autores Beretta e Bozzolan (2004), Ereira (2007), Kongprajya (2010), Linsley e Shrives (2006), Liu (2006) e Serrasqueiro (2011) concluíram que o número de divulgações referentes ao risco não financeiro apresentava-se, significativamente, superior ao número de divulgações de risco financeiro. Dado que este estudo se centra no anexo, é expectável um maior volume de divulgação relacionada com o risco financeiro, uma vez que as maiores exigências se centram neste tipo de risco, sendo assim definida a hipótese que se segue:

H1: A divulgação de matérias ligadas ao risco apresenta-se significativamente superior no que toca ao risco financeiro comparativamente com o risco não financeiro.

\subsubsection{A divulgação de "boas notícias" vs. "más notícias"}

Assumindo que o RC é um meio para as entidades controlarem a sua reputação no mercado (Kongprajya, 2010; Linsley \& Shrives, 2006), as entidades tendencialmente preferem divulgar "boas notícias" (positivas). Nesse sentido, é expetável que a divulgação das "boas notícias" supere a divulgação das "más notícias", uma vez que a entidade tende a encobrir as "más notícias" de forma a não prejudicar a sua reputação no mercado (Skinner, 1994). A causa destas "más notícias", é normalmente atribuída a eventos externos à própria entidade (Abrahamson \& Park, 1994; Beretta \& Bozzolan, 2004), de modo que a natureza da informação divulgada pode ser entendida pela teoria da atribuição.

Por outro lado, se as entidades não divulgarem "más notícias", isso seria interpretado de forma em que se estaria a esconder algum problema (Deegan \& Gordon, 1996). Assim, com base na teoria da legitimidade, os administradores diminuem os proprietary costs e, consequentemente, aumentam a sua credibilidade perante o mercado, ao divulgar as "más notícias" (Oliveira et al., 2011ª).

No estudo de Serrasqueiro (2011), embora não havendo muita discrepância no número de registos, a informação divulgada referente a "más notícias" apresentava-se superior às "boas notícias", ao passo que Ereira (2007), Linsley e Shrives (2006) e Oliveira et al. (2011ª) concluíram que a informação divulgada apresentava-se maioritariamente positiva. Nesse sentido, e com base na revisão de literatura anteriormente apresentada, a próxima hipótese encontra-se definida nos seguintes termos:

H2: A divulgação de matérias ligadas ao risco apresenta-se significativamente superior no que toca às "boas notícias" comparativamente com as "más notícias".

\subsubsection{A divulgação "forward" vs. "backward"}

Um dos problemas associados à informação futura é a sua incerteza. No entanto, a informação referente ao futuro é mais útil aos utilizadores do que o risco referente ao passado (Linsley \& Shrives, 2006).

Linsley e Shrives (2000) referem que a divulgação de informação forward é uma informação incerta, e os administradores têm medo que a sua insegurança possa expô-los a possíveis reclamações, ao 
passo que a informação forward é mais útil para os stakeholders, para a sua tomada de decisão, do que a informação backward. É provável que os diretores fiquem relutantes em divulgar informação sobre o risco futuro, tanto como em quantificar esse risco.

Apesar de Linsley e Shrives (2006) e Serrasqueiro (2011) terem registado que a informação divulgada sobre o risco apresentava-se voltada para o futuro, nos estudos de Beretta e Bozzolan (2004), Ereira (2007), Lajili e Zéghal (2005), Liu (2006) e Oliveira et al. (2011a, 2011b), a informação relativa ao risco apresentava-se tendencialmente focada no passado.

Assim, e tendo em conta a realidade identificada pela maioria dos estudos, foi definida a seguinte hipótese:

H3: A divulgação de matérias ligadas ao risco apresenta-se significativamente superior no que toca à informação backward comparativamente com a informação forward.

\subsubsection{A divulgação "qualitativa" vs. "quantitativa"}

De acordo com alguns autores, para melhorar a qualidade da informação divulgada, as diversas entidades devem quantificar, o quanto possível, a dimensão do risco a que estão sujeitas (Beretta \& Bozzolan, 2004; Linsley \& Shrives, 2006). A informação quantitativa torna-se mais relevante para os diversos investidores (Oliveira et al., 2011a), uma vez que esta quantificação do risco fornece uma imagem mais clara/desobstruída do resultado previsto desse risco (Kongprajya, 2010), o que reduz as incertezas e melhora a transparência e a eficiência do mercado (Oliveira \& Rodrigues, 2011). Também Beretta e Bozzolan (2004) referem que esta quantificação do risco por parte das entidades possibilita aos diversos utilizadores da informação terem uma ideia do impacto que esses riscos vão ter na entidade.

Na prática, esta quantificação do risco em termos monetários não é de fácil aplicabilidade (Kongprajya, 2010). Um dos problemas que se coloca à quantificação desses riscos é a subjetividade, dado que esta informação depende muito do julgamento de quem a prepara (Kongprajya, 2010); outra questão relaciona-se com a falta de dados e de possíveis censuras futuras (aos administradores por terem usado o bom senso para estimar a dimensão do risco, quando o resultado desse risco difere da estimativa inicialmente divulgada) (Linsley \& Shrives, 2006). Estas problemáticas de divulgar informação quantitativa, faz com que as entidades tenham uma maior propensão a divulgarem mais informação qualitativa do que quantitativa. Beretta e Bozzolan (2004), Lajili e Zéghal (2005), Linsley e Shrives (2006), Oliveira et al. (2011a) e Serrasqueiro (2011) registaram que a informação divulgada sobre o risco é essencialmente qualitativa. Assim, e no sentido dos estudos anteriores, a próxima hipótese apresenta-se da seguinte forma:

H4: A divulgação de matérias ligadas ao risco apresenta-se significativamente superior no que toca à informação qualitativa comparativamente à informação quantitativa.

\subsection{Caracterização da metodologia}

\subsubsection{População}

Para a realização do presente estudo, recorreu-se, inicialmente, à identificação das entidades cotadas, em 31 de Dezembro de 2012, no índice Portuguese Stock Index (PSI) Geral da New York Stock Exchange (NYSE) Euronext Lisbon - Bolsa de Valores de Lisboa. Esta escolha assenta no facto de estas entidades apresentarem o seu RC de uma forma acessível ao público em geral.

O acesso à informação foi obtido por meio da consulta à página web da NYSE Euronext de Lisboa. Os dados analisados no presente estudo foram obtidos a partir da recolha dos RC consolidados, relativos ao pe- 
ríodo contabilístico anual findo em 31 de Dezembro de 2011 e 2012, correspondendo, assim, numa primeira fase, a uma abordagem baseada, fundamentalmente, na análise de conteúdo. Importa ressalvar que, para a realização do estudo, foram excluídos as Sociedades Anónimas Desportivas (SAD), por apresentarem um período de relato diferente do ano civil e diferente do período das outras entidades que constituem a população, bem como as entidades não sedeadas no território nacional e as sociedades financeiras, por questões igualmente relacionadas com a comparabilidade da informação. Foram igualmente excluídas, para garantia de uma maior comparabilidade, as entidades que remetem a sua divulgação do risco para outra componente do RC que não o anexo, nomeadamente, o Relatório de Gestão. Pretende-se ainda que a análise seja feita em termos de amostra constante ao longo dos dois anos propostos para este estudo, o que faz com que a seleção das entidades tenha subjacente a divulgação ininterrupta de informação nesse período. Assim, e após os critérios de seleção anteriormente referidos, um total de 36 entidades integrantes do PSI Geral foram incluídas na população deste estudo.

A Tabela 1 apresenta a seleção das entidades em estudo.

Tabela 1

Entidades que constituem a população

\begin{tabular}{lc} 
& N. ${ }^{\circ}$ empresas \\
\hline Total entidades cotadas na Euronext Lisbon a 31/12/2012 & 48 \\
\hline Entidades excluídas devido: & 3 \\
$\quad$ Ano contabilístico diferente (SAD) & 7 \\
Sociedades Financeiras & 2 \\
\hline Entidades sem informação no anexo & 36 \\
\hline Total de entidades incluídas no estudo & \\
\hline
\end{tabular}

Em Portugal, são conhecidos alguns estudos que já anteriormente analisaram a divulgação relativa ao risco por parte das entidades nacionais, designadamente, os trabalhos de Ereira (2007), Oliveira et al. (2011a, 2011b) e Serrasqueiro (2011). No entanto, diferentemente de Oliveira et al. (2011b), o presente estudo não incorpora unicamente as instituições de crédito portuguesas com os relatórios publicados no Banco de Portugal. Por outro lado, distintamente de Serrasqueiro (2011), este estudo não se centra nas entidades não financeiras do PSI 20 mas, sim, nas entidades não financeiras do PSI Geral da NYSE Euronext Lisbon.

O presente estudo distingue-se também dos trabalhos de Ereira (2007) e Oliveira et al. (2011a), uma vez que a metodologia destes autores incidiu sobre o relatório de corporate governance e sobre o relatório de gestão, respetivamente, e este estudo centra-se na análise de conteúdo do anexo (exclusivamente) de cada uma das entidades que integram o estudo. A escolha do anexo como documento base da análise de conteúdo recai sobre o fato de ser um documento obrigatório e regulamentado, em que o seu conteúdo é de fácil comparação entre as diversas entidades.

\subsubsection{Definição das variáveis}

Tendo em conta o objetivo deste estudo, nomeadamente, a identificação da divulgação relativa do risco prevista em diversas fontes legais (IAS/IFRS e CSC), foram identificados os seguintes items que estão na origem dos referidos requisitos, e que se encontram desenvolvidos nas linhas seguintes:

- As sociedades devem prestar informação, no anexo às contas, sobre a natureza e o objetivo comercial das operações não incluídas no balanço e o respetivo impacto financeiro, quando os riscos ou os benefícios resultantes de tais operações sejam relevantes e na medida em que a divulgação de tais riscos ou benefícios seja necessária para efeitos de avaliação da situação financeira da sociedade (CSC, art. 66-A, n. ${ }^{\circ} 1$, alínea a));

- Divulgar a informação numa base de continuidade, e caso não se verifique, divulgar as incertezas que possam lançar essas dúvidas (IAS $1, \S 25-26$ ); 
- A entidade deve divulgar informação sobre as premissas que fizer sobre o futuro e outras fontes importantes de incerteza na estimativa no final do período de relatório, que possuam um risco significativo de resultar em um ajuste relevante nos valores contabilísticos de ativos e passivos dentro do próximo exercício financeiro (IAS 1, \$125-133).

A recolha da informação relativa à divulgação do risco tem presente a necessidade de caraterização/ classificação das frases a partir dos atributos definidos em cada hipótese, nomeadamente:

- Quanto à natureza da informação: se a informação é financeira ou não financeira;

- Quanto às caraterísticas da informação: se são "boas notícias", "más notícias" ou "notícias neutras";

- Quanto ao âmbito temporal da informação: se diz respeito ao passado ou ao futuro; e

- Quanto ao caráter da informação: se a informação é qualitativa ou quantitativa.

A classificação das frases, em termos da natureza da informação, pretende identificar se a informação divulgada se refere a riscos financeiros ou a riscos não financeiros, nomeadamente, os riscos operacionais, os riscos de liderança e gestão, os riscos de informação e tenológicos, os riscos de integridade e os riscos de estratégia.

Outra classificação possível refere-se às caraterísticas da informação, ou seja, se as frases transmitem notícias boas, notícias más ou sem qualquer impacto (a informação é considerada como notícias positivas se tiver ou potencialmente vir a ter impacto no negócio).

A classificação em torno do âmbito futuro ou passado respeita à perspetiva temporal implícita em cada uma das frases, ou seja, se se referem ao passado ou ao futuro.

Por fim, a classificação quanto ao caráter da informação refere-se à explicitação em termos monetários ou não monetários do item de divulgação. Uma vez que o risco pode ser divido em distintas categorias, foi utilizado a categorização do risco efetuada nos estudos de Ereira (2007), Kongprajya (2010) e Linsley e Shrives (2006) apresentados na Figura 1:

\begin{tabular}{|c|c|}
\hline Tipo de Risco & Atributo de divulgação \\
\hline Risco Financeiro & $\begin{array}{l}\text { - taxa de juro } \\
\text { - taxa de câmbio } \\
\text { - risco de liquidez } \\
\text { - risco de crédito }\end{array}$ \\
\hline Risco Operacional & $\begin{array}{l}\text { - satisfação do cliente } \\
\text { - desenvolvimento do produto } \\
\text { - eficiência e desempenho } \\
\text { - obsolescência de stock } \\
\text { - falha no produto ou do serviço } \\
\text { - saúde e segurança }\end{array}$ \\
\hline Risco de Liderança e Gestão & $\begin{array}{l}\text { - liderança e gestão } \\
\text { - outsorcing } \\
\text { - incentivos de desempenho } \\
\text { - comunicação }\end{array}$ \\
\hline $\begin{array}{l}\text { Risco de Informação e } \\
\text { Risco Tecnológico }\end{array}$ & $\begin{array}{l}\text { - integridade } \\
\text { - disponibilidade } \\
\text { - infra-estrutura }\end{array}$ \\
\hline Risco de Integridade & $\begin{array}{l}\text { - fraudes } \\
\text { - atos ilegais }\end{array}$ \\
\hline Risco de Estratégia & $\begin{array}{l}\text { - avaliação ambiental e do desempenho } \\
\text { - indústria/concorrentes } \\
\text { - preços } \\
\text { - planeamento } \\
\text { - vida útil } \\
\text { - regulamentos/ política }\end{array}$ \\
\hline
\end{tabular}

Figura 1. Atributos de divulgação do risco

Fonte: Linsley e Shrives (2006) 
Como é possível observar na Figura 1, e tendo em conta a natureza da informação, o risco pode ser dividido em diversas categorias, nomeadamente em: risco financeiro e risco não financeiro, que inclui o risco operacional; o risco de liderança e gestão ${ }^{1}$; o risco de informação e tecnológico; o risco de integridade; e o risco de estratégia.

Para a categorização das frases, será efetuada uma primeira leitura aos relatórios de gestão com classificações provisórias das frases, de forma a criar regras de decisão quanto às classificações que se pretendiam efetuar. Após esta primeira leitura, realizou-se uma segunda leitura, de forma a categorizar as frases definitivamente. Na sequência da categorização definitiva das frases, foi elaborado um teste quanto à consistência das categorizações, comparando-se frases com o mesmo tipo de risco e validando, desse modo, a classificação efetuada. Este procedimento foi igualmente seguido por Ereira (2007).

Assim, além da definição dos items de divulgação do risco (para a categorização das frases), foi necessário criar regras de decisão. Estas regras foram estabelecidas de acordo com a grelha que serviu de base ao estudo de Linsley e Shrives (2006), identificadas na sequência:

- Para identificar as divulgações do risco, deve ser adotada uma definição clara de risco.

- As frases são codificadas como divulgações do risco se nelas existir uma informação de qualquer oportunidade ou perigo, dano, ameaça ou exposição, que já tenha tido ou venha a ter um impacto sobre a entidade.

- Embora a definição de risco seja ampla, as divulgações de risco devem ser claramente indicadas, não podendo ser informações implícitas.

- As divulgações de risco devem ser registadas e classificadas de acordo com o Figura 2.

- As divulgações de risco quantitativas são as divulgações que divulgam claramente o impacto financeiro do risco ou divulgam informações suficientes para que o leitor possa calcular o impacto financeiro desse risco.

- No caso de a frase em análise ter mais que uma classificação possível, as informações serão classificadas na categoria de risco com mais destaque (ênfase).

- As tabelas (com informação tanto quantitativa ou qualitativa) que fornecem informação do risco devem ser interpretadas como frases.

- A informação quantitativa contida nas tabelas será classificada como monetária e neutra, de modo a tornar a informação o mais possível objetiva e evitar juízos de valor que enviesem a análise.

- No caso de haver repetição nas frases divulgadas, esta deve ser registada cada vez que seja mencionada.

- No caso de a divulgação ser muito vaga na sua referência ao risco, então não deve ser registada.

1 Tradução livre no autor. No original: empowerment. 
Para a categorização dos RC, foi necessário utilizar uma grelha de registo da informação divulgada, ilustrado no Figura 2, para que no final da análise de conteúdo se tenha a informação sintetizada.

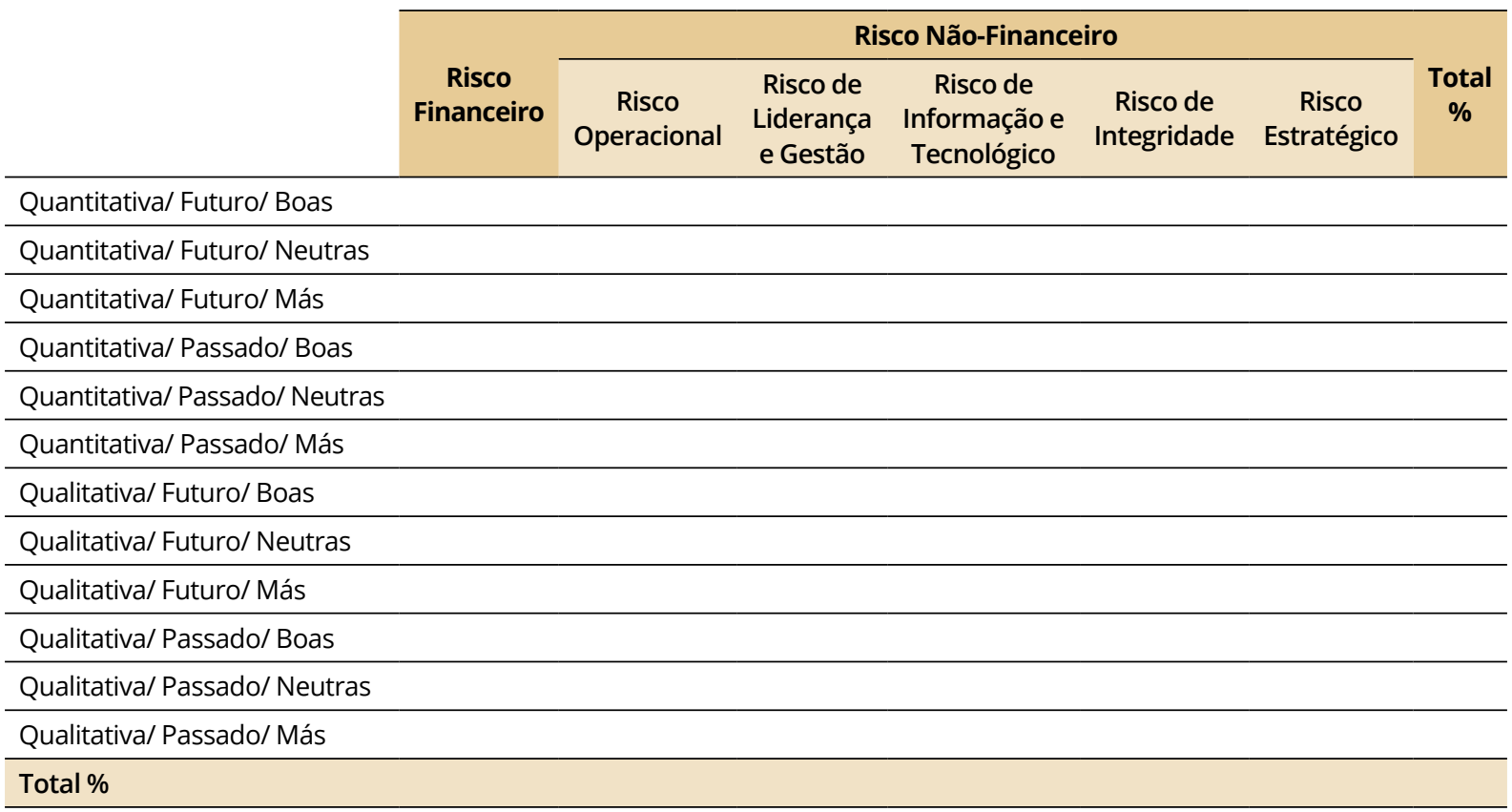

Figura 2. Matriz de divulgação do risco

Após o preenchimento da grelha referenciada na Figura 2 para cada uma das entidades incluídas no estudo, elaborou-se um quadro resumo com o nome das entidades e com o número de divulgações que cada uma continha referentes a cada tipo de risco, bem como o total de divulgações por entidade.

\subsubsection{Técnicas utilizadas}

De forma a analisar as hipóteses anteriormente apresentadas, foi utilizada neste estudo, para além de técnicas de estatística descritiva (em que cada variável é analisada isoladamente), uma técnica estatística bivariada (análise que relaciona duas variáveis no contexto de cada análise). Para as hipóteses definidas, em que se torna necessária a comparação de dados extraídos da mesma população em distintos períodos ou situações de análise, será utilizado o teste de Wilcoxon.

O tratamento estatístico da informação foi realizado com o suporte do software Predictive Analytics SoftWare (PASW). O nível de significância (ou $p$-value) é a probabilidade de obter-se resultados fora da região de possibilidades de conclusão. Se o $p$-value for inferior a $5 \%$, nos termos do nível de significância adotado no presente estudo, verifica-se a existência de diferenças significativas entre as variáveis em estudo.

No capítulo seguinte, apresenta-se a discussão dos resultados, tendo em conta os objetivos definidos e as linhas metodológicas anteriormente referenciadas. 


\section{Apresentação e discussão dos resultados obtidos}

Este capítulo tem por objetivo analisar os resultados obtidos a partir dos testes estatísticos efetuados no sentido de validar (ou não) as hipóteses desenvolvidas na parte precedente desta investigação.

\subsection{Risco financeiro vs. risco não financeiro $(\mathrm{H} 1)$}

No contexto desta hipótese, relativa à análise da natureza do risco, foi inicialmente elaborada uma análise descritiva do número de frases divulgadas no anexo por cada ano em análise. Em seguida, será apresentada uma caracterização estatística da análise de conteúdo efetuada ao risco divulgado no anexo por parte das entidades.

Assim, na Tabela 2, apresenta-se, de uma forma sintetizada, as caraterísticas da informação divulgada pelas diversas entidades constituintes da população em estudo. A partir dos resultados obtidos, é possível concluir que o grau de divulgação encontra-se dependente do tipo/natureza de risco envolvido. Desse modo, verifica-se que as entidades divulgam muito mais informação relativa ao risco financeiro do que ao risco não financeiro. No âmbito do risco não financeiro, existe, por sua vez, uma grande diversidade na quantidade de risco divulgado, isto porque existem categorias de risco que são muito mais divulgadas do que outras. Relativamente ao risco não financeiro, constata-se que o risco mais divulgado é o risco operacional, por oposição ao risco de integridade, sendo divulgado nos anos analisados uma única vez (representando apenas $0,11 \%$ ).

Tabela 2

\section{Análise estatística: Caraterísticas da informação divulgada}

\begin{tabular}{|c|c|c|c|c|c|c|c|}
\hline & & & & & & & \\
\hline & & $\begin{array}{c}\text { Risco } \\
\text { Financeiro }\end{array}$ & $\begin{array}{c}\text { Risco } \\
\text { Operacional }\end{array}$ & $\begin{array}{c}\text { Risco } \\
\text { Gestão e } \\
\text { Liderança }\end{array}$ & $\begin{array}{c}\text { Risco de } \\
\text { Informação e } \\
\text { Tecnológico }\end{array}$ & $\begin{array}{c}\text { Risco } \\
\text { Integridade }\end{array}$ & $\begin{array}{c}\text { Risco } \\
\text { Estratégico }\end{array}$ \\
\hline \multirow{5}{*}{2011} & Total & 645 & 223 & 3 & 5 & 1 & 19 \\
\hline & $\%$ & $72 \%$ & $25 \%$ & $0 \%$ & $1 \%$ & $0 \%$ & $2 \%$ \\
\hline & média & 18 & 6 & 0 & 0 & 0 & 1 \\
\hline & máximo & 41 & 40 & 3 & 5 & 1 & 11 \\
\hline & mínimo & 6 & 0 & 0 & 0 & 0 & 0 \\
\hline \multirow{5}{*}{2012} & Total & 629 & 219 & 3 & 5 & 1 & 19 \\
\hline & $\%$ & $72 \%$ & $25 \%$ & $0 \%$ & $1 \%$ & $0 \%$ & $2 \%$ \\
\hline & média & 17 & 6 & 0 & 0 & 0 & 1 \\
\hline & máximo & 33 & 40 & 3 & 5 & 1 & 11 \\
\hline & mínimo & 5 & 0 & 0 & 0 & 0 & 0 \\
\hline
\end{tabular}

Em relação ao risco operacional, refira-se que este representa cerca de $24 \%$, com 223 e 219 divulgações durante o ano de 2011 e 2012, respetivamente; ao passo que o risco financeiro registou o triplo das divulgações, tanto em 2011 como em 2012.

Nas divulgações registadas ao longo do ano de 2011, é possível concluir que, em média, as entidades divulgaram 18 frases de risco financeiro e 7 frases de risco não financeiro por divulgação (no anexo). Pode referir-se, ainda, que o máximo de informação divulgada por entidade relativamente ao risco financeiro foi de 41, e de risco não financeiro rondou as 60. Identificam-se situações, pela análise do valor mínimo, de não divulgação de risco não financeiro, contrariamente à informação divulgada referente ao risco financeiro, que registou sempre divulgações por parte das entidades, com um mínimo de 6 frases divulgadas. 
Analisando as divulgações relativas ao ano de 2012, conclui-se que, em média, foram divulgadas no anexo 17 frases referentes à informação de risco financeiro e apenas 7 frases referentes à informação de risco não financeiro. No que toca ao número mínimo de informação divulgada, este apresenta um valor inferior a 2011, com apenas 5 frases divulgadas referentes a risco financeiro e nenhuma divulgação para os restantes tipos de risco. Quando analisado o máximo de frases divulgadas, conclui-se que o valor de informação referente ao risco financeiro é inferior ao ano de 2011, com apenas 33 frases, e que se mantém o máximo de frases divulgadas no que toca ao risco não financeiro, com 60 divulgações identificadas para o risco operacional.

À semelhança das hipóteses anteriores, foi inicialmente elaborada uma análise comparativa do número de frases divulgadas no anexo por ano, sendo possível identificar que o ano de 2011 é aquele que apresenta o maior volume de informação divulgada, com uma média de cerca de 25 frases por divulgação. O número médio de frases divulgadas no ano de 2012 não difere muito e apresenta, por sua vez, cerca de 24 frases por divulgação e um total de 876 frases divulgadas.

Os resultados da análise comparativa encontram-se na Tabela 3.

Tabela 3

Análise estatística: Natureza da informação divulgada

\begin{tabular}{cccccc} 
& N & Média & Desvio Padrão & Mínimo & Máximo \\
\hline RF_2011 & 645 & 17,92 & 7,751 & 6 & 41 \\
\hline RNF_2011 & 251 & 6,97 & 10,761 & 0 & 51 \\
\hline RT_2011 & 896 & 24,89 & 15,131 & 6 & 77 \\
\hline RF_2012 & 629 & 17,47 & 6,922 & 5 & 33 \\
\hline RNF_2012 & 247 & 6,92 & 10,715 & 0 & 51 \\
\hline RT_2012 & 876 & 24,39 & 14,944 & 7 & 79 \\
\hline
\end{tabular}

Ainda com base na Tabela 3, é de salientar a existência de um desvio padrão elevado entre a quantidade de informação divulgada pelas diversas entidades, o que demonstra que algumas entidades apresentam um volume de informação muito reduzido (cerca de 7 frases por divulgação), por oposição a outras entidades que apresentam mais de 70 frases no seu anexo.

Com o objetivo de identificar a existência de diferenças estatisticamente significativas na quantidade de informação divulgada em cada um dos anos em análise, foi aplicado o teste de Wilcoxon. Tais resultados são apresentados na Tabela 4 .

Tabela 4

Teste Wilcoxon: Quantidade de informação divulgada

\begin{tabular}{|c|c|c|c|c|c|}
\hline & 2011 & 2012 & RF & RNF & RT \\
\hline & $\begin{array}{l}\text { RNF_2011 - } \\
\text { RF_2011 }\end{array}$ & $\begin{array}{l}\text { RNF_2012 - } \\
\text { RF_2012 }\end{array}$ & $\begin{array}{l}\text { RF_2012 - } \\
\text { RF_2011 }\end{array}$ & $\begin{array}{l}\text { RNF_2012- } \\
\text { RNF_2011 }\end{array}$ & $\begin{array}{l}\text { RT_2011 - } \\
\text { RT_2012 }\end{array}$ \\
\hline z & $-4,393^{a}$ & $-4,394^{a}$ &,$- 339^{a}$ &,$- 364^{b}$ &,$- 064^{b}$ \\
\hline Asymp. Sig. (2-tailed) & ,000 & ,000 & ,735 & ,716 & ,949 \\
\hline
\end{tabular}

a. Based on positive ranks | b. Based on negative ranks | c. Wilcoxon Signed Ranks Test

Os resultados apresentados na Tabela 4 demonstram, tendo em conta a probabilidade de significância (Asymp. Sig 2-tailed) definida para este estudo $(p<0,05)$, diferentes constatações.

Assim, por um lado, os distintos tipos de riscos divulgados no mesmo ano (Risco Não Financeiro (RNF)_2011 - Risco Financeiro (RF))_2011 e RNF_2012 - RF_2012) assumem valores que permitem afirmar que as diferenças apresentam-se estatisticamente significativas (Asymp. Sig. (2-tailed) de 0,00). 
Tais resultados permitem validar a $\mathrm{H} 1$ definida, apresentando-se, no entanto, inconsistentes com as evidências internacionais identificadas anteriormente, nomeadamente, por Beretta e Bozzolan (2004), Ereira (2007), Kongprajya (2010), Linsley e Shrives (2006), Liu (2006) e Serrasqueiro (2011). A referida inconsistência deriva, sobretudo, conforme já mencionado, da utilização de distintas fontes na comparação entre este e os anteriores estudos, visto que este centra-se distintamente na análise do anexo como fonte de informação, onde é expectável um maior número de divulgações relacionada com matérias financeiras.

Por outro lado, na comparação entre o mesmo tipo de risco (RF e RNF) divulgado em anos diferentes (2012 vs. 2011), não se verificam diferenças significativas. Com efeito, constata-se que essas diferenças (RF_2012 - RF_2011, RNF_2012 - RNF_2011 e Risco Total (RT)_2011 - RT_2012) assumem valores que não permitem afirmar que se apresentem estatisticamente significativas (Asymp. Sig. (2-tailed) de 0,735, de 0,716 e de 0,949 respetivamente). Efetivamente, em detrimento de um aumento, verifica-se mesmo uma ligeira redução na quantidade de informação divulgada relativamente a cada um dos tipos de risco em análise. Tal efeito deriva, provavelmente, da técnica do "copy-paste", presente nos RC das entidades, como referido, designadamente, por Liu (2006).

\subsection{Boas vs. más notícias $(\mathrm{H} 2)$}

Esta hipótese pretende analisar a divulgação do risco, com o objetivo de identificar se as entidades, durante o período de 2011 e 2012, divulgaram um maior número de informação considerada "boa" ou "má".

Foi elaborada, inicialmente, uma análise comparativa da qualidade da informação divulgada no anexo relativamente à sua natureza (se a informação divulgada é boa ou má), cujos resultados se encontram na Tabela 5. Pela sua análise, é possível identificar que o ano de 2011 apresenta um maior volume de informação divulgada, com um valor de 279 frases divulgadas no anexo. O número de frases que divulgaram informação classificada como "boa" foi de 186 frases, em oposição às 93 frases divulgadas com informação considerada como "má".

No entanto, é de salientar a existência de um desvio padrão elevado entre a quantidade de frases que as diversas entidades divulgam sobre informação "boa", o que demonstra que algumas delas apresentam um volume de informação muito reduzido, havendo mesmo entidades que não divulgam uma única frase dessa natureza, por oposição a outras entidades que apresentam 23 frases.

Tabela 5

Análise estatística: Natureza da informação divulgada

\begin{tabular}{|c|c|c|c|c|c|c|}
\hline & & $\mathbf{N}$ & Média & Desvio Padrão & Mínimo & Máximo \\
\hline \multirow{6}{*}{2011} & Boas RF & 119 & 3,31 & 2,617 & 0 & 10 \\
\hline & Boas & 67 & 1,86 & 3,944 & 0 & 18 \\
\hline & Boas RT & 186 & 5,17 & 4,966 & 0 & 23 \\
\hline & Mas RF & 17 & 0,47 & 1,108 & 0 & 5 \\
\hline & Mas RNF & 76 & 2,11 & 3,717 & 0 & 16 \\
\hline & Mas RT & 93 & 2,58 & 4,292 & 0 & 21 \\
\hline \multirow{6}{*}{2012} & Boas RF & 109 & 3,03 & 2,443 & 0 & 10 \\
\hline & Boas & 61 & 1,69 & 3,853 & 0 & 18 \\
\hline & Boas RT & 170 & 4,72 & 5,108 & 0 & 24 \\
\hline & Mas RF & 20 & 0,56 & 1,107 & 0 & 5 \\
\hline & Mas RNF & 78 & 2,19 & 4,348 & 0 & 22 \\
\hline & Mas RT & 98 & 2,75 & 4,982 & 0 & 27 \\
\hline
\end{tabular}


Com o objetivo de identificar a existência de diferenças, estatisticamente significativas, na natureza da informação divulgada, em cada um dos anos em análise, foi aplicado o teste de Wilcoxon. Tais resultados são apresentados na Tabela 6.

Tabela 6

Teste de Wilcoxon: Natureza da informação divulgada

\begin{tabular}{ccccccc} 
& \multicolumn{3}{c}{2011} & \multicolumn{2}{c}{2012} \\
\cline { 2 - 7 } & $\begin{array}{c}\text { Mas RF - } \\
\text { Boas RF }\end{array}$ & $\begin{array}{c}\text { Mas RNF - } \\
\text { Boas RNF }\end{array}$ & $\begin{array}{c}\text { Mas RT - } \\
\text { Boas RT }\end{array}$ & $\begin{array}{c}\text { Mas RF - } \\
\text { Boas RF }\end{array}$ & $\begin{array}{c}\text { Mas RNF - } \\
\text { Boas RNF }\end{array}$ & $\begin{array}{c}\text { Mas RT - } \\
\text { Boas RT }\end{array}$ \\
\hline $\mathrm{z}$ & $-4,358^{\mathrm{a}}$ &,$- 027^{\mathrm{a}}$ & $-3,233^{\mathrm{a}}$ & $-4,315^{\mathrm{a}}$ &,$- 330^{\mathrm{b}}$ & $-3,100^{\mathrm{a}}$ \\
\hline Asymp. Sig (2-tailed) &, 000 &, 978 &, 001 &, 000 &, 742 &, 002 \\
\hline
\end{tabular}

No que se refere à comparação da natureza da informação divulgada, os resultados identificados na Tabela 6 apresentam-se divergentes. Tendo em conta a probabilidade de significância (Asymp. Sig (2-tailed)) definida para este estudo $(p<0,05)$, constata-se que apenas numa das situações não se verificam diferenças significativas. Com efeito, constata-se que as diferenças entre a informação má e boa, quando se trata de RNF (Más RNF - Boas RNF), assumem valores que não permitem afirmar que essas diferenças se apresentam estatisticamente significativas (Asymp. Sig (2-tailed) de 0,978 e 0,742 para 2011 e 2012 respetivamente). Por outro lado, os resultados que traduzem as diferenças entre a natureza da informação, boa e má, quando divulgam RF e RT (Más RF - Boas RF e Más RT - Boas RT), apresentam-se estatisticamente significativas, dado que o valor da probabilidade de significância (Asymp. Sig (2-tailed)) é de 0,000 e 0,001, respetivamente, para o ano de 2011, e de 0,000 e 0,002, respetivamente, para o ano de 2012.

Denote-se que a natureza da informação divulgada é feita de forma diferenciada, verificando-se que se divulga mais informação boa que informação má. Estes resultados estão em linha com as evidências obtidas por Ereira (2007), Linsley e Shrives (2006) e Oliveira et al. (2011a).

\subsection{Backward vs. forward (H3)}

Esta hipótese pretende identificar a tendência da informação divulgada pelas entidades cotadas em Portugal em termos de âmbito temporal, ou seja, se a informação é direcionada para o futuro ou se relacionada com efeitos passados.

À semelhança das hipóteses anteriores, foi inicialmente elaborada uma análise comparativa do número de frases divulgadas no anexo por ano, cujos resultados se apresentam na Tabela 7. 
Análise estatística: Âmbito temporal da informação divulgada

\begin{tabular}{cllcccc} 
& & N & Média & Desvio Padrão & Mínimo & Máximo \\
\hline \multirow{5}{*}{2011} & Passado RF & 635 & 17,639 & 7,616 & 6 & 40 \\
\cline { 2 - 7 } & Passado RNF & 173 & 4,806 & 9,251 & 0 & 43 \\
\cline { 2 - 7 } & Passado RT & 808 & 22,444 & 13,781 & 6 & 69 \\
\cline { 2 - 7 } & Futuro RF & 10 & 0,278 & 0,882 & 0 & 5 \\
\cline { 2 - 7 } & Futuro RNF & 78 & 2,167 & 3,13 & 0 & 14 \\
\cline { 2 - 7 } & Futuro RT & 88 & 2,444 & 3,707 & 0 & 30 \\
\hline \multirow{5}{*}{2012} & Passado RF & 617 & 17,14 & 6,681 & 5 & 43 \\
\cline { 2 - 7 } & Passado RNF & 172 & 4,78 & 9,169 & 0 & 71 \\
\cline { 2 - 7 } & Passado RT & 789 & 21,92 & 13,338 & 7 & 5 \\
\cline { 2 - 7 } & Futuro RF & 12 & 0,33 & 0,986 & 0 & 22 \\
\cline { 2 - 7 } & Futuro RNF & 75 & 2,08 & 3,945 & 0 & 71 \\
\cline { 2 - 7 } & Futuro RT & 87 & 2,42 & 4,662 & 0 & 519 \\
\hline
\end{tabular}

É possível identificar, com base na Tabela 7, que, no ano de 2011, a informação divulgada pelas entidades foi maioritariamente sobre acontecimentos passados, com 808 divulgações, ao passo que a informação divulgada sobre impactos futuros foi apenas de 88 divulgações. No entanto, é de salientar a existência de um desvio padrão elevado entre a quantidade de informação divulgada pelas diversas entidades, o que demonstra que algumas entidades apresentam um volume de informação muito reduzido (chegando a não ter uma única frase por divulgação), em oposição a entidades que apresentam mais de 69 frases no seu anexo. Verifica-se, ainda, que a variação na informação divulgada não se altera significativamente de um ano para o outro. Relativamente a 2012, verifica-se a mesma realidade, ou seja, há uma diferença bastante significativa entre as divulgações de RF quando referente ao passado ou ao futuro. Quando se analisa as divulgações do RNF, esta diferença nas divulgações não é tão acentuada como acontece no caso das divulgações relativas ao RF, embora se verifique igualmente mais informação divulgada relativa ao passado do que ao futuro.

$\mathrm{Na}$ sequência, e atendendo à metodologia delineada anteriormente, recorreu-se ao teste de Wilcoxon para verificar eventuais diferenças estatisticamente significativas entre o nível de divulgação do risco e o âmbito temporal da informação por parte das entidades em estudo. Perante este cenário, a Tabela 8 apresenta os resultados obtidos.

Tabela 8

Teste de Wilcoxon: Âmbito temporal da informação divulgada

\begin{tabular}{ccccccc} 
& \multicolumn{3}{c}{2011} & \multicolumn{2}{c}{2012} \\
\cline { 2 - 7 } & $\begin{array}{c}\text { Futuro RF - } \\
\text { Passado RF }\end{array}$ & $\begin{array}{c}\text { Futuro RNF - } \\
\text { Passado RNF }\end{array}$ & $\begin{array}{c}\text { Futuro RT - } \\
\text { Passado RT }\end{array}$ & $\begin{array}{c}\text { Futuro RF - } \\
\text { Passado RF }\end{array}$ & $\begin{array}{c}\text { Futuro RNF - } \\
\text { Passado RNF }\end{array}$ & $\begin{array}{c}\text { Futuro RT - } \\
\text { Passado RT }\end{array}$ \\
\hline $\mathrm{z}$ & $-5,234^{\mathrm{a}}$ & $-1,442^{\mathrm{a}}$ & $-5,234^{\mathrm{a}}$ & $-5,235^{\mathrm{a}}$ & $-1,930^{\mathrm{a}}$ & $-5,218^{\mathrm{a}}$ \\
\hline Asymp. Sig. (2-tailed) &, 000 &, 149 &, 000 &, 000 &, 054 &, 000 \\
\hline
\end{tabular}

Tendo em conta a probabilidade de significância (Asymp. Sig (2-tailed)) definida para este estudo $(p<0,05)$, os resultados identificados na Tabela 8 apresentam-se contraditórios relativamente ao RNF. Enfatiza-se que, em 2012, em quaisquer dos cenários, se verificam diferenças significativas entre a informação "Futura" e "Passada" consoante estejam em causa informação de RF, RNF e RT. Estas diferenças assumem 
valores que permitem afirmar que são diferenças estatisticamente significativas (Asymp. Sig. (2-tailed) de 0,000 , de 0,054 e de 0,000 respetivamente). Na mesma linha, está o resultado que traduz a diferença entre a informação "Futura" e "Passada" de RF e RT para 2011, dado que o seu valor é de 0,000 para ambos os casos (sendo, por isso, estatisticamente significativo a um nível de significância inferior a 0,05).

Dos resultados obtidos, pode-se confirmar que se divulgou mais informação de matérias ligadas ao passado que ao futuro e que tais diferenças são estatisticamente significativas no contexto do RF. Tais resultados estão em linha de conta com os estudos de Beretta e Bozzolan (2004), Ereira (2007), Lajili e Zéghal (2005), Liu (2006) e Oliveira et al. (2011a, 2011b).

\subsection{Qualitativa vs. quantitativa $(\mathrm{H} 4)$}

Esta hipótese, pretende verificar se, tendencialmente, a informação divulgada pelas diferentes entidades pertencentes à nossa população é maioritariamente qualitativa ou quantitativa. Nesse sentido, foi desenvolvida uma análise descritiva relativamente à informação divulgada de forma qualitativa e quantitativa. Tais resultados apresentam-se na Tabela 9.

Tabela 9

\section{Análise estatística: Caráter da informação divulgada}

\begin{tabular}{|c|c|c|c|c|c|c|}
\hline & & & & & & \\
\hline & & $\mathbf{N}$ & Média & Desvio Padrão & Mínimo & Máximo \\
\hline \multirow{6}{*}{2011} & Quantitativa RF & 85 & 2,361 & 2,031 & 0 & 7 \\
\hline & Quantitativa RNF & 121 & 3,361 & 4,865 & 0 & 21 \\
\hline & Quantitativa RT & 206 & 5,722 & 5,868 & 0 & 26 \\
\hline & Qualitativa RF & 560 & 15,556 & 7,149 & 6 & 39 \\
\hline & Qualitativa RNF & 130 & 3,611 & 9,415 & 0 & 44 \\
\hline & Qualitativa RT & 690 & 19,167 & 12,473 & 6 & 64 \\
\hline \multirow{6}{*}{2012} & Quantitativa RF & 81 & 2,250 & 1,991 & 0 & 7 \\
\hline & Quantitativa RNF & 110 & 3,083 & 4,094 & 0 & 17 \\
\hline & Quantitativa RT & 191 & 5,333 & 4,980 & 0 & 22 \\
\hline & Qualitativa RF & 548 & 15,222 & 6,419 & 5 & 32 \\
\hline & Qualitativa RNF & 137 & 3,833 & 9,425 & 0 & 44 \\
\hline & Qualitativa RT & 685 & 19,056 & 12,264 & 6 & 66 \\
\hline
\end{tabular}

Constata-se, a partir da referida tabela (Tabela 9), que o número de divulgações de forma quantitativa referente ao RNF é bastante superior às divulgações referentes ao RF para ambos os anos em análise. A informação divulgada de forma qualitativa é bastante superior quando comparada em termos de natureza da informação, ou seja, a informação divulgada referente ao RF é superior em mais do dobro comparativamente com a divulgação do RNF para ambos os anos. Pode-se concluir, ainda, que as entidades têm necessidades diferentes de divulgação de informação, uma vez que, da presente população, há entidades que não divulgam frases tanto de forma qualitativa como quantitativa e outras entidades que divulgam mais de 60 frases (realidade verificada em ambos os anos). De forma a reconhecer a existência de diferenças estatisticamente significativas relativamente ao caráter da informação divulgada, foi aplicado o teste de Wilcoxon. Tais resultados são apresentados na Tabela 10. 
Tabela 10

Teste de Wilcoxon: Caráter da informação divulgada

\begin{tabular}{ccccccc}
\cline { 2 - 7 } & \multicolumn{3}{c}{$\mathbf{2 0 1 1}$} & \multicolumn{2}{c}{$\mathbf{2 0 1 2}$} \\
\cline { 2 - 7 } & $\begin{array}{c}\text { Qualit RF - } \\
\text { Quantit RF }\end{array}$ & $\begin{array}{c}\text { Qualit RNF - } \\
\text { Quantit RNF }\end{array}$ & $\begin{array}{c}\text { Qualit RT - } \\
\text { Quantit RT }\end{array}$ & $\begin{array}{c}\text { Qualit RF - } \\
\text { Quantit RF }\end{array}$ & $\begin{array}{c}\text { Qualit RNF - } \\
\text { Quantit RNF }\end{array}$ & $\begin{array}{c}\text { Qualit RT - } \\
\text { Quantit RT }\end{array}$ \\
\hline z & $-5,236^{\mathrm{a}}$ & $-1,855^{\mathrm{b}}$ & $-4,851^{\mathrm{a}}$ & $-4,315^{\mathrm{a}}$ &,$- 330^{\mathrm{b}}$ & $-3,100^{\mathrm{a}}$ \\
\hline Asymp. Sig. (2-tailed) &, 000 &, 064 &, 000 &, 000 &, 742 &, 002 \\
\hline
\end{tabular}

a. Based on positive ranks | b. Based on negative ranks | c. Wilcoxon Signed Ranks Test

Tendo em conta a probabilidade de significância (Asymp. Sig (2-tailed)) definida para este estudo $(p<0,05)$, os resultados obtidos na Tabela 10 evidenciam a existência de diferenças estatisticamente significativas. Em 2011, em quaisquer dos cenários, verificam-se diferenças significativas entre a informação divulgada de forma qualitativa e quantitativa, consoante esteja em causa a informação relativa ao RF e ao RT (Qualit RF - Quant RF e Qualit RT - Quant RT) com uma Asymp. Sig. (2-tailed) de 0,000 para ambos os casos. Na mesma linha está o resultado que traduz a diferença entre a informação qualitativa e quantitativa de RNF (Qualit RNF - Quant RNF), para 2011, dado que o seu valor é de 0,064, sendo, por isso, estatisticamente significativo apenas a um nível de significância de 0,10 .

Em relação ao ano de 2012, não se verificam diferenças significativas entre a informação divulgada de forma qualitativa e quantitativa de RNF. Com efeito, constata-se que tais divergências entre a informação divulgada de forma qualitativa e quantitativa de RNF (Qualit RNF - Quant RNF) assumem valores que não permitem afirmar que existam diferenças estatisticamente significativas. Porém, verificam-se diferenças estatisticamente significativas entre a informação de forma qualitativa e quantitativa, consoante estejam em causa informação de RF e RT (Qualit RF - Quant RF e Qualit RT - Quant RT), tendo em conta a probabilidade de significância associada (Asymp. Sig. (2-tailed) de 0,000 e de 0,002, respetivamente.

Esta análise permite afirmar que se divulgou muito mais informação de forma qualitativa do que quantitativa. Os resultados obtidos estão em linha com os estudos de Beretta e Bozzolan (2004), Lajili e Zéghal (2005), Linsley e Shrives (2006), Oliveira et al. (2011a) e Serrasqueiro (2011).

A última parte deste artigo destina-se a apresentar as principais conclusões oriundas dos diversos estudos efetuados e apresentados anteriormente, tendo em conta as distintas hipóteses previamente definidas, bem como as principais limitações e perspetivas futuras identificadas.

\section{Conclusões, limitações e futuras investigações}

Esta última parte do artigo destina-se a divulgar as principais conclusões obtidas, as limitações encontradas e possíveis contribuições para futuras investigações identificadas no contexto da divulgação de matérias ligadas ao risco, temática proposta neste estudo.

\subsection{Conclusões}

Neste capítulo, serão apresentadas as conclusões obtidas relativamente à análise das características da informação divulgada em matérias ligadas ao risco por parte das entidades que integram o PSI Geral, ao longo do ano de 2011 e 2012, nomeadamente, o risco financeiro vs. não financeiro (H1), boas vs. más notícias (H2), a informação backward vs. forward $(\mathrm{H} 3)$ e, por fim, a informação qualitativa $v s$. quantitativa (H4). As análises relacionadas com as distintas características da informação, anteriormente referidas, têm em conta as hipóteses definidas na Metodologia. 
Assim, o objetivo da $\mathrm{H} 1$ passava por analisar o tipo de informação divulgada durante o período, ou seja, se a informação divulgada encontrava-se maioritariamente relacionada com risco financeiro ou com risco não financeiro. Perante este cenário, os resultados obtidos a partir do teste de correlação de Wilcoxon permitiram obter suporte para a $\mathrm{H} 1$, demonstrando, em linha com a literatura sobre o tema, que as entidades divulgaram mais informação relativa a matérias ligadas ao risco financeiro em oposição ao risco não financeiro. Tal constatação está em linha com a maior relevância, geralmente atribuída pelas entidades, às matérias de natureza financeira no anexo, objeto deste estudo, para as quais é habitualmente percecionado um maior nível de risco por parte dos utilizadores da informação.

Os resultados obtidos para a H2, por sua vez, tendo em conta os resultados do teste de Wilcoxon, permitiram validar a referida hipótese, sugerindo que a informação "boa" apresenta um maior grau de divulgação, comparativamente com a "má" informação. Uma vez mais confirmando a literatura, este resultado evidencia a ênfase geralmente atribuída à informação qualificada como "boa", o que pode indiciar algum grau de enviesamento na informação divulgada pelas entidades.

A hipótese seguinte (H3) pretendia analisar a informação divulgada em uma perspetiva temporal. Dos resultados obtidos através da análise de Wilcoxon, foi possível suportar com adequada fiabilidade a H3, confirmando-se um maior grau de informação de matérias ligadas ao passado do que ao futuro. De facto, os resultados mostram-se adequados à ideia, geralmente defendida na literatura, segundo a qual a informação financeira apresenta-se fortemente concentrada no elemento confirmatório, em oposição ao preditivo indiciador de um elevado conservadorismo da informação divulgada.

Por sua vez, a $\mathrm{H} 4$ baseou-se no caráter da informação divulgada. As análises realizadas permitiram obter um razoável suporte para a referida hipótese, podendo-se concluir pela existência de um maior nível de informação apresentada sob a forma qualitativa, comparativamente com a sua forma de apresentação quantitativa, realidade verificada para ambos os anos em análise. De certo modo, a referida constatação fortalece as ideias anteriormente apresentadas, associadas, por um lado, a um maior enviesamento da informação sobre o risco divulgado nas demonstrações financeiras, na medida em que esta se apresenta de uma forma menos objetiva; e, por outro, a um maior nível de conservadorismo, na medida em que apresenta um menor grau de objetividade relativamente ao nível de risco que resulta da avaliação realizada pela própria entidade. Em ambos os casos, está em causa o risco passível de ser atribuído à entidade, sob distintos pontos de vista, por parte dos utilizadores.

Este trabalho apresenta algumas limitações, nomeadamente, o reduzido número de entidades que estão incluídas no PSI Geral, não permitindo a análise da possível influência de outros fatores, como o setor empresarial. Outro aspeto que pode ser apontado como limitação relaciona-se com o facto de a análise utilizar, exclusivamente, dois anos consecutivos de informação.

Como sugestões para futuras investigações, poderia ser interessante averiguar as diferenças de divulgação entre as entidades cotadas e as não cotadas, de forma a compreender se existem diferenças no comportamento de divulgação de informação, bem como se as entidades cotadas/não cotadas divulgam informação meramente mandatária ou de forma voluntária.

A existência de um período de estudo mais alargado do que o utilizado permitiria, por sua vez, obter indicações mais consistentes e robustas para as hipóteses já propostas neste estudo.

Pretende-se que os resultados desta investigação contribuam para a identificação dos elementos que se encontram na base da divulgação de informação de matérias ligadas ao risco no anexo das DF das entidades cotadas. 


\section{Referências Bibliográficas}

Abraham, S., \& Cox, P. (2007). Analysing the determinants of narrative risk information in UK: FTSE 100 annual reports. The British Accounting Review, 39(3), pp. 227-248. DOI: 10.1016/j.bar.2007.06.002

Abraham, S., \& Shrives, P. (2014). Improving the relevande of risk factor disclosure in corporate annual reports. The British Accounting Review, 46(1), pp. 91-107. DOI: 10.1016/j.bar.2013.10.002.

Abrahamson, E. \& Park, C. (1994). Concealment of negative organizational outcomes: an agency theory perspective. Academy of Management Journal, 37(5), pp. 1302-1334. DOI: 10.2307/256674.

Alves, C. A. (2005). A divulgação do risco operacional segundo recomendações do comité da Basiléia: Estudos em bancos com carteira comercial no Brasil. Dissertação de Mestrado, Universidade Federal do Paraná, Paraná, Brasil. Recuperado em 15 fevereiro, 2013, em http://dspace.c3sl.ufpr.br/dspace/bitstream/handle/1884/3010/Disserta;jsessionid=4A330818680296579CCE5ABA89E3C61D?sequence $=1$.

Beattie, V., Mcinnes, B. \& Fearnley, S. (2004). A methodology for analysing and evaluating narratives in annual reports: a comprehensive descriptive profile and metrics for disclosure quality attributes. Accounting Forum, 28(3), pp. 205-236. DOI: 10.1016/j.accfor.2004.07.001.

Beretta, S. \& Bozzolan, S. (2004). A framework for the analysis of firm risk communication. The International journal of Accounting, 39(3), pp. 265-288. DOI: 10.1016/j.intacc.2004.06.006.

Código das Sociedades Comerciais. 29a ed, Lisboa, Portugal: Almedina. ISBN 978-972-40-5370-7.

Deegan, C. \& Gordon, B. (1996). A study of the environmental practices of Australian corporations. Accounting and Business Research, 26(3), pp. 187-199. DOI: 10.1080/00014788.1996.9729510.

Deumes, R. (2008). Corporate risk reporting: A content analysis of narrative risk disclosures in prospectuses. Journal of Business Communication, 45(2), pp. 120-157. DOI: 10.1177/0021943607313992.

Deumes, R. \& Knechel, W. R. (2008). Economic incentives for voluntary reporting on internal risk management and control systems. Auditing: a Journal of Practice \& Theory, 27 (1), pp. 35-66. DOI: 10.2308/aud.2008.27.1.35.

Dobler, M. (2008). Incentives for risk reporting - A discretionary disclosure and a cheap talk approach. The International Journal of Accounting, 43(2), pp. 184-206. DOI: 10.1016/j.intacc.2008.04.005.

Ereira, S. (2007). O relato do risco - Uma análise no contexto das empresas cotadas na Euronext Lisbon. Dissertação de Mestrado, Instituto Politécnico de Leiria: Escola Superior de Tecnologia e Gestão, Leiria, Portugal. Recuperado em 15 fevereiro, 2013, em http://hdl.handle.net/10316/9694.

Guthrie, J., Petty, R., Yongvanich, K \& Ricceri, F. (2004). Using content analysis as a research method to inquire into intellectual capital reporting. Journal of Intellectual Capital, 5(2), pp. 282-293. DOI: 10.1108/14691930410533704.

Hassan, M. (2012). Risk narrative disclosure strategies to enhance organizational legitimacy: Evidence from UAE financial institutions. International Journal of Disclosure and Governance, 11, pp. 1-17. DOI: $10.1057 /$ jdg.2012.11.

Hernández-Madrigal, M., Blanco-Dopico, M. I. \& Aibar-Guzmán, B. (2012). The influence of mandatory requirements on risk disclosure practices in Spain. International Journal of Disclosure and Governance, 9, pp. 78-99. DOI: 10.1057/jdg.2011.22.

Höring, D. \& Gründl, H. (2011). Investigating risk disclosure practices in European insurance industry. The International Association for the Study of Insurance Economics, 36, pp. 380-413. DOI: 10.1057/ gpp.2011.13. 
International Accounting Standardrs Board (IASB). (2011). International Accounting Standard (IAS) $\mathrm{n}^{\circ}$ 1: Apresentação das demonstrações financeiras. Recuperado em 5 fevereiro, 2013, em http://www. ifrs.org/IFRSs/IFRS-technical-summaries/Documents/Port2011/IAS1.pdf.

Jiang, N. (2008). Examining risk management and risk disclosures practices in UK public companies. Dissertação de Mestrado, Universidade de Nottingham, Nottingham, Inglaterra.

Johansson, S. \& ThÖonberg, S. (2011). Risk Disclosures in Listed Companies: Exploring the Swedish Context. Dissertação de Mestrado, Universidade de Kristianstad, Kristianstad, Suécia. Recuperado em 15 fevereiro, 2013, em http://www.diva-portal.org/smash/get/diva2:435268/FULLTEXT01.pdf

Kongprajya, C. (2010). The study of corporate risk disclosure in the case of Thai listed companies. Dissertação de Mestrado, Universidade de Nottingham, Nottingham, Inglaterra. Recuperado em 15 fevereiro, 2013, em http://eprints.nottingham.ac.uk/11546/1/Chalida_Kongprajya_(4097185).pdf.

Lajili, K. \& Zéghal, D. (2005). A content analysis of risk management disclosures in Canadian annual reports. Canadian Journal of Administrative Sciences, 22(2), pp. 125-142. DOI: 10.1111/j.19364490.2005.tb00714.x.

Lemos, K. M. \& Rodrigues, L. L. (2011). Estudo do Grau de Cumprimento com as Recomendações do Basel Committee on Banking Supervision e da Organisation of Securities Commissions, sobre divulgação de informação relacionada com instrumentos derivados, pelas entidades portuguesas pertencentes ao sector bancário. Congresso AECA: "Nuevo modelo económico: Empresa, Mercados y Culturas", Granada, Espanha, 16. Recuperado em 5 abril, 2012, em http://www.aeca.es/pub/on_ line/comunicaciones_xvicongresoaeca/cd/67a.pdf.

Linsley, P. \& Shrives, P. J. (2000). Risk management and reporting risk in the UK. Journal of Risk, 3(1), pp. 115-129.

Linsley, P. \& Shrives, P. J. (2006). Risk reporting: A study of risk disclosures in the annual reports of UK companies. The British Accounting Review, 38(4), pp. 387-404. DOI: 10.1016/j.bar.2006.05.002.

Liu, Y. (2006). A content analysis of external risk reporting in UK public telecommunications companies. Dissertação de Mestrado, Universidade de Nottingham, Nottingham, Inglaterra.

Meijer, M. (2011). Risk disclosures in annual reports of Dutch listed companies during the years 2005-2008. Dissertação de Mestrado, Universidade de Twente, Overijssel, Holanda. Recuperado em 15 fevereiro, 2011, em http://essay.utwente.nl/61150/.

Michiels, A. (2008). Corporate risk reporting practices in annual reports of Belgian companies: Intelligent risks or risky intelligence. Recuperado em 6 fevereiro, 2012, em URL: <http://doclib. uhasselt.be/ dspace/bitstream/1942/8633/1/03206 692007411c.pdf $>$.

Oliveira, J. \& Rodrigues, L. L. (2011). Risk reporting practices among non-financial companies: Evidence from Portugal. Recuperado em 5 novembro, 2012, em http://ria.ua.pt/bitstream/10773/6833/1/ Risk_reporting_practices_among_non-inancial_companies._Evidence_from_Portugal.pdf.

Oliveira, J., Rodrigues, L. L. \& Craig, R. (2011a). Risk related disclosure by Non-finance Companies: Portuguese practices and disclosure characteristics. Managerial Auditing Journal, 26(9), pp. 817-839. DOI: $10.1108 / 02686901111171466$.

Oliveira, J., Rodrigues, L. L. \& Craig, R. (2011b). Risk related disclosure practices in the annual reports of Portuguese credit institutions: An exploratory study. Journal of Banking Regulation, 12(2), pp. 100118. DOI: $10.1057 /$ jbr.2010.20.

Puga, J. (2012). Relato dos riscos empresariais nas empresas da Euronext Lisbon. Dissertação de mestrado. Universidade de Aveiro: Instituto Superior de Contabilidade e Administração, Aveiro, Portugal. Recuperado em 10 junho, 2015, em http://hdl.handle.net/10773/10982. 
Rajab, B. \& Handley-Schachler, M. (2009). Corporate risk disclosure by UK firms: Trends and determinants. World Review of Entrepreneurship Management and Sustainable Development, 5(3), pp. 224243. DOI: 10.1504/WREMSD.2009.026801.

Semper, D. \& Beltrán, J. (2014). Risk disclosure and cost of ofequity: The Spanhis case. Contaduría y Administración, 59(4), pp. 105-135. DOI: 10.1016/S0186-1042(14)70157-3.

Serrasqueiro, R. (2011). Corporate risk disclosure by non financial Portuguese firms in the prospectus between 2007 and 2009 Congresso AECA: "Nuevo modelo económico: Empresa, Mercados y Culturas”, Granada, Espanha, 16. Recuperado em 5 abril, 2012, em URL: <http://www.aeca.es/xvicongresoaeca/principal.htm>.

Skinner, D. J. (1994). Why firms voluntary disclose bad news. Journal of Accounting Research, 32(1), pp. 3860. Recuperado em 15 fevereiro, 2013, em http://sites.fas.harvard.edu/ ec970lt/Readings/April_20/ Skinner\%201994.pdf.

Slovic, P., Fischhoff, B. \& Lichtenstein, S. (1980). Facts and fears: Understanding perceived risk. R. New York: Plenum. Schwing and W. A. Albers Jr.. DOI: 10.1007/978-1-4899-0445-4_9.

Solomon, J. F., Solomon, A., Norton, S. \& Joseph, N. (2000). A conceptual framework for corporate risk disclosure emerging from the agenda for corporate governance reform. British accounting Review, 32(4), pp.447-478. DOI: 10.1006/bare.2000.0145.

Taylor, G., Tower, G. \& Neilson, J. (2010). Corporate communication of financial risk. Accounting and Finance, 50 (2), pp. 417-446. DOI: 10.1111/j.1467-629X.2009.00326.x.

Tröster, K. (2005). The extent and determinants of narrative disclosures of risk management in annual reports of UK listed companies. [Working Paper Series]. Poole, Inglaterra: Bournemouth University. Recuperado em 15 fevereiro, 2013, em http://ibal.bmth.ac.uk/pdf_docs/439.pdf.

Vandemaele, S., Vergauwen, P. \& Michiels, A. (2009). Management risk reporting practices and their determinants: A study of Belgian listed firms. Recuperado em 6 outubro, 2012, em https://uhdspace. uhasselt.be/dspace/handle/1942/9392>.

Yampolskaya, N. (2006). Risk disclosure in UK companies annual reports. Dissertação de mestrado, Universidade de Nottingham, Nottingham, Inglaterra.

Zadeh, F. \& Eskandari, A. (2012). Firm size as company's characteristic and level of risk disclosure: review on theories and literatures. International Journal of Business and Social Science, 3(17), pp. 9-17. Recuperado em 15 fevereiro, 2013, em http://ijbssnet.com/journals/Vol_3_No_17_September_2012/2.pdf. 